\title{
Synthesis of A Sustainable Sago-Based Value Chain via Fuzzy Optimisation Approach
}

\author{
Jeffrey Hong Seng Chong ${ }^{1}$, Yoke Kin Wan ${ }^{1,1}$, and Viknesh Andiappan ${ }^{2}$ \\ ${ }^{1}$ School of Engineering, Taylor's University, Subang Jaya, Selangor, Malaysia. \\ ${ }^{2}$ School of Engineering and Physical Sciences, Heriot-Watt University Malaysia, 62200, Putrajaya, \\ Wilayah Persekutuan Putrajaya, Malaysia
}

\begin{abstract}
Sago starch is one of the staple foods for human, especially in Asia's Region. It can be produced via sago starch extraction process (SSEP). During the SSEP, several types of sago wastes are generated such as sago fiber (SF), sago bark (SB) and sago wastewater (SW). With the increase in production of existing factories and sago mills, the sago industrial practice in waste disposal management is gaining more attention, thus implementation of effective waste management is vital. One of the promising ways to have effective waste management is to create value out of the sago wastes. In a recent study, sago-based refinery, which is a facility to convert sago wastes into value-added products (e.g., bio-ethanol and energy) was found feasible. However, the conversion of other value added products from sago wastes while considering the environmental impact has not been considered in sago value chain. Therefore, an optimum sago value chain, which involved conversion activities of sago wastes into value-added products, is aimed to be synthesised in this work. The optimum sago value chain will be evaluated based on profit and carbon emissions using fuzzy-based optimisation approach via a commercial optimisation software, Lingo 16.0. To illustrate the the developed approach, an industrial case study has been solved in this work.
\end{abstract}

\section{Introduction}

Sago palm (Metroxylan Sagu) is one of the underutilised crops that can potentially produce staple food for human, especially in Asia's Region. The sago palm produces sago starch which contains high carbohydrates that can be obtained from the trunks of sago palm. Such palm is an excellent crop for sustainable agriculture due to its ability to thrive in most soil conditions and it requires only one time planting that has the ability of self-sustain by producing its young tree, also known as suckers or tillers [1]. It can also be served as an income for poverty alleviation as it is commonly planted in rural areas [2]. Karim et al. [3] states that, under optimal farming practices, up to 25 metric tonnes of sago starch per hectare annually can be achieved, which is roughly $3-4$ times the starch yield of staple crops such as rice (6 tonnes/ha/yr) or wheat (5 tonnes/ha/yr) [2], [4]. Sago starch can be produced via sago starch extraction process (SSEP) as shown in Figure 1. As shown, there

${ }^{1}$ Corresponding author: YokeKin.Wan@taylors.edu.my 
are several types of sago wastes that are generated during the process, namely sago fiber $(\mathrm{SF})$, sago bark (SB) and sago wastewater (SW)[4].

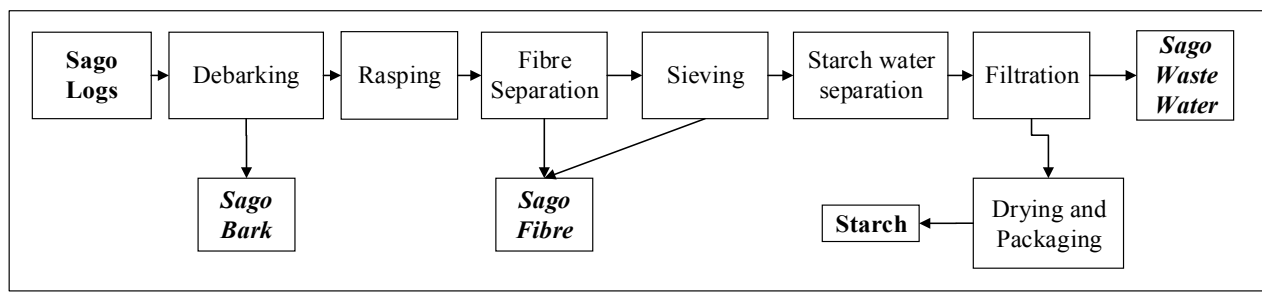

Fig. 1. Block Flow Diagram of SSEP

In current industrial practices, SB is used as timber fuel for firing or will be disposed around the mills to be used as flooring material [4]. SF is used as animal feed, otherwise, it will be released into nearby streams along with SW. According to Adeni et al. [5], SW, combined with SF, represents high organic materials, chemical oxygen demand (COD) and biochemical oxygen demand (BOD), which does not comply to the discharged regulations set in Environmental Quality Act, 1974. The installation of pollution control devices can be costly, approximately $20-50 \%$ of the total investment for a large scale production mill, which is not preferred by producers in this relatively low value commodity industry [5]. SF and $\mathrm{SB}$, which are lignocellulosic waste $(\mathrm{LCW})$, contains residue starch which can be converted into value added products such as glucose, which can be further refined to higher value product such as bio-fuels.

To address the aforementioned issues, a viable alternative is to create value out of the sago wastes to improve the current performance of sago value chain. As mentioned, SF and SB could be utilised for the production of value added products (i.e., ethanol, organic acids, enzymes and others)[6]. However, the idea of converting sago wastes into valuable products is still in its infancy. In most recently, Wan et al. [7] studied the feasibility of a sago-based refinery, which is a facility to convert sago wastes into value-added products (e.g., bio-ethanol and energy). The study results showed that it is feasible to convert sago wastes (SB and SF) into bioethanol and energy in sago-based refinery. In addition, Wan and her co-authors [8] also conducted a value chain analysis for sago industry to determine the optimum value chain pathway for sago industry. Value chain is a set of activities that are done to design, produce, market, deliver and support the product created by a party [9]. First proposed by Michael Porter, value chain divides break down a chain of activities into individual parts to scrutinise the dynamics of activities in order to reveal its strength and weaknesses, thus identifying value creation opportunities. Application of value chain in the sago industry has been pioneered by a study done by Wan et al. [8], whom developed a value chain to improve the sustainability of the industry to identify value creation opportunities. However, the conversion of sago wastes into value-added products had not been considered in the sago value chain. Therefore, in order to further improve the economic and environmental performance of the sago value chain, this study aims to expand the previous work done by Wan et al [8], by introducing alternatives towards utilisation of sago wastes to create value added products while considering the environmental impact done to the sago value chain. Figure 2 showed the sago value chain done by Wan et al. [8] and the sago value chain has been expanded in this work by considering value added product conversion technologies (i.e., technology 1, intermediates products, technology 2, and value-added products). 


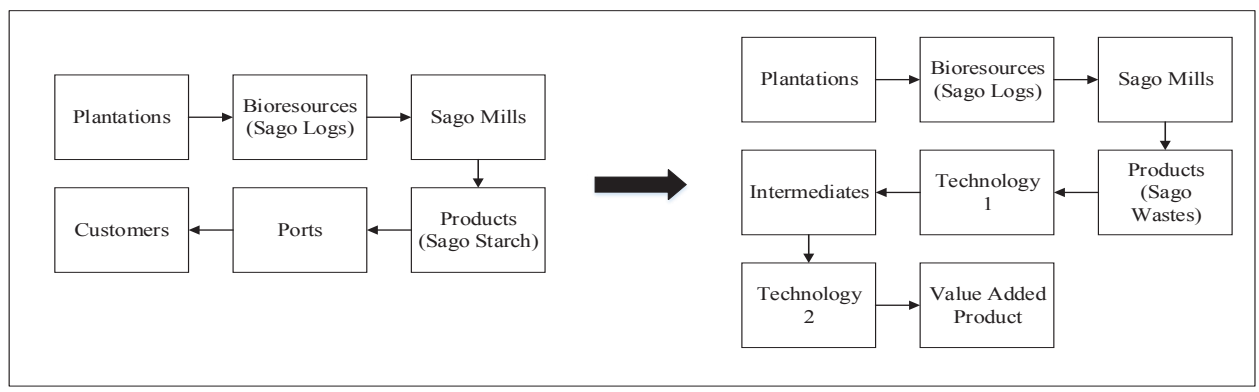

Fig. 2. Proposed Value Chain of Sago Industry in this Study

Douglas et al. [10] adapted fuzzy-based optimisation approach based on 'max-min' aggregation to synthesis of a sustainable integrated bio-refinery. The author's study did not identify the optimal value chain in the sago industry. However, the author has proven that fuzzy-based optimisation approach can be used to obtain an optimal pathway from a superstructure, while considering the economic and environmental impact. Therefore, in order to further improve the economic and environmental performance of the sago value chain, this study aims to expand the previous work done by Wan et al. [8], by introducing alternatives towards utilisation of sago wastes to create value added products to maximise profit, while minimising environmental impact done of the sago value chain. To determine the optimum pathway in this, a fuzzy-based optimisation approach will be developed in this work to find an optimal solution to the multi-objective model in this study. To illustrate the application of proposed model, a real industrial case study has been solved.

\section{Methodology}

A generic wastewater treatment superstructure is first developed to show all possible pathway to treat wastewater as shown in Figure 1. Based on this generic superstructure, MFCA-based approach has been developed by formulating mathematical equations for each treatment in WWTP as shown in following sections. These equations included mass balance equation, contaminant equation, and cost computation equations. To demonstrate the developed approach, an industry case study, organic wastewater treatment plant is solved.

\subsection{Generic superstructure of wastewater treatment}

Fig. 3 illustrates the methodology using the fuzzy-based optimisation approach. First step is to determine the superstructure based on the layers of activities from the proposed value chain in this study. Then, the objectives of the study have to be set and relevant data needs to be collected based on the objective set. In this study, the objective of maximising profit and minimising CFP of the sago value chain is set for synthesis of an optimal value chain for sago waste conversion. Profit and CFP objectives are contradictory. Therefore, a fuzzybased optimisation approach has to be developed. Douglas et al. [10] Following the fuzzybased optimization approach, the mass balance has to be formulated, as well as the formulation of equations necessary for all objective functions, which in this case, is the profit and CFP equations. The developed formulations are then solved using a commercial optimization software Lingo V.16. 


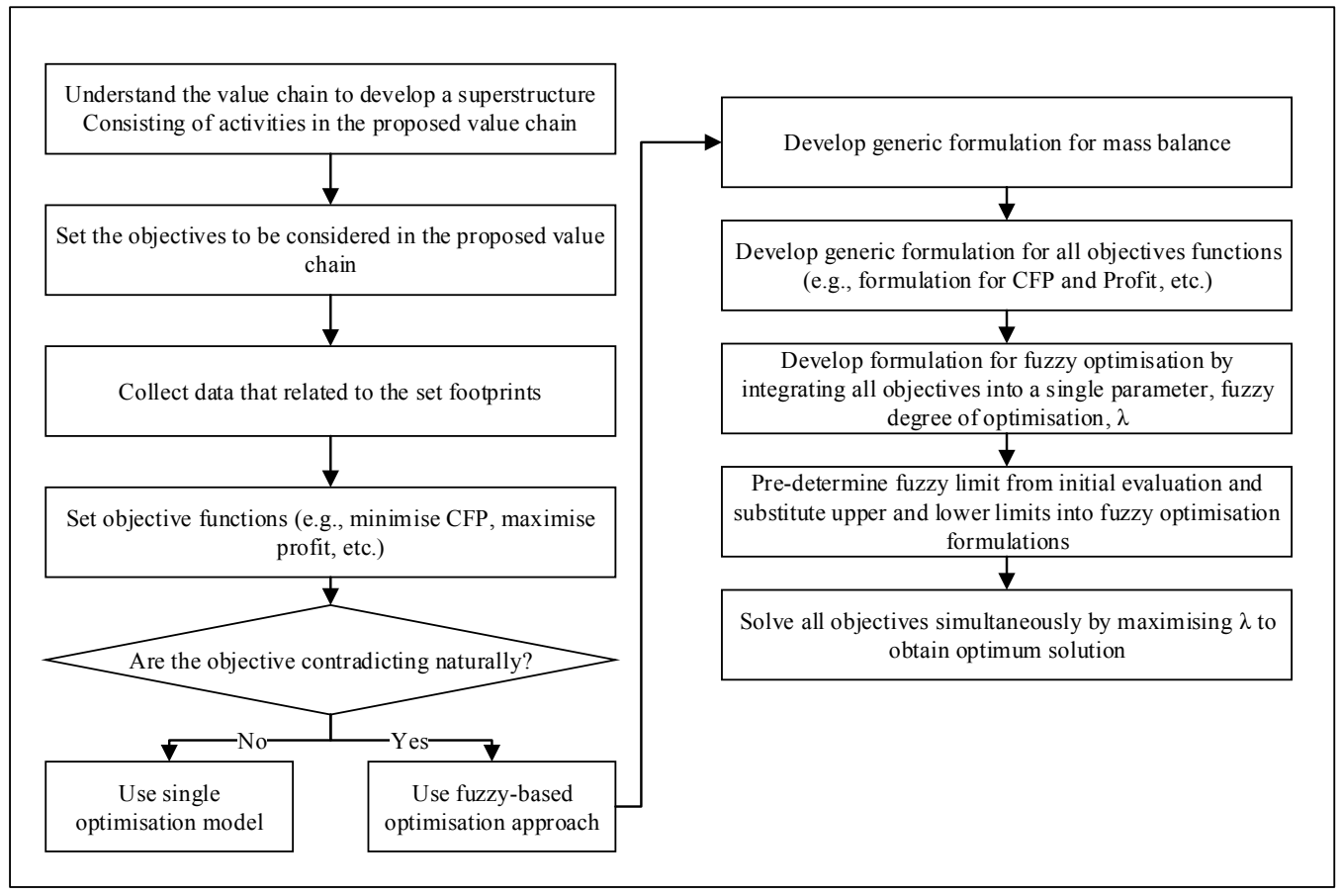

Fig. 3. Methodology Flow Chart for Fuzzy-Based Optimisation Approach

To illustrate the alternatives stages of the value chain, superstructure is first developed. As shown in Figure 4, the superstructure illustrates the seven layers of activities that is considered in the value chain proposed in this study. With reference to the approach used by Wan et al. [8], the activity starts from the harvesting palms from a set of plantation $g \in G$ with annual available palm $\mathrm{F}_{\mathrm{g}}^{\mathrm{av}}$, processed and converted to a set of bio-resource $m \in M$, which is limited to only sago logs in this study. The sago logs are then sent to a set of sago mill $f \in F$ with starch production capability $\mathrm{F}_{\mathrm{f}}^{\text {starch.lim }}$. The sago mill $f$ turns the bio-resource $m$ into a set product $p \in P$ based on the amount of starch produced from the sago mill, which in the case of this study, represents the sago wastes. In the study of Wan et al.[8], the product considered in the author's study is just sago starch in the product $p$ layer. However, in this study, sago starch would not be focused, unlike as shown in the works of Wan et al. [8]. Sago wastes (e.g., SB, SF, SW) will be considered in this study instead.

The sago waste is then sent to a set of conversion technologies $1 c \in C$ to produce a set of Intermediate product $d \in D$. Intermediate product $d$ is then sent for further processing in a set of technology $2 e \in E$ to produce a set of end product $z \in Z$. To model this superstructure, mathematical equations have been formulated in following sections. 


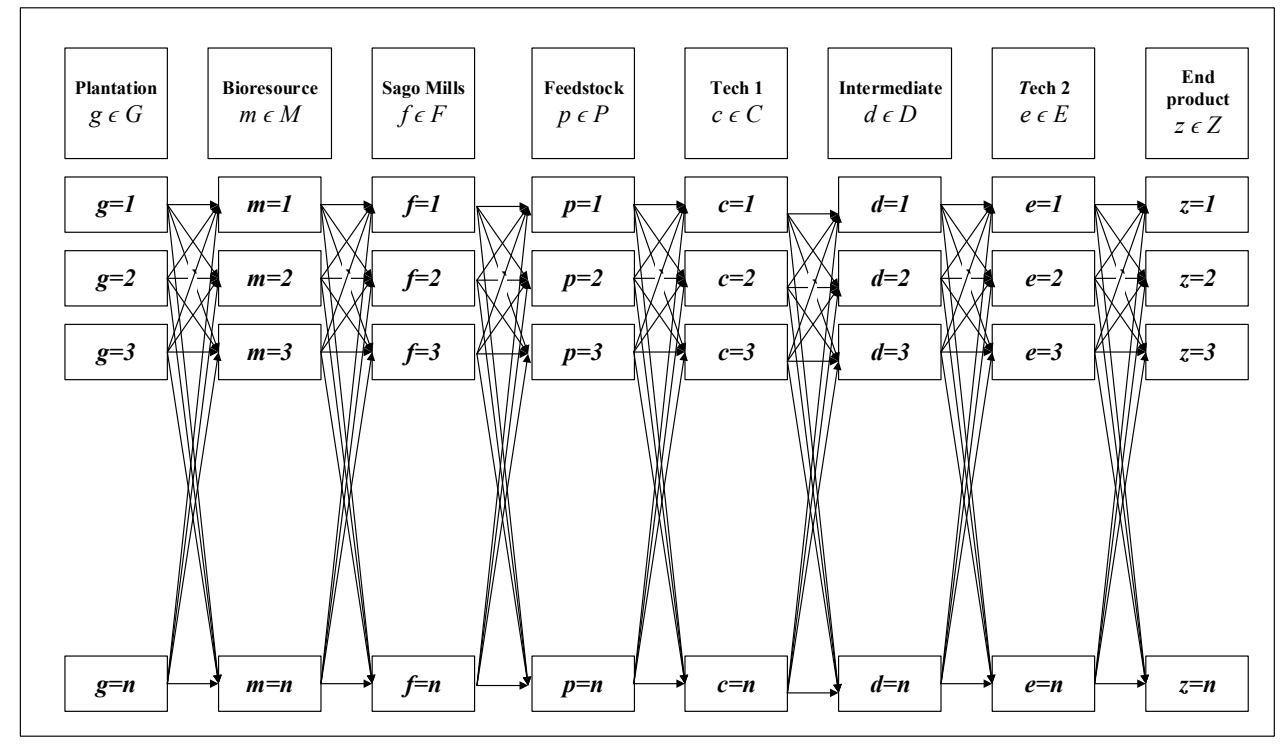

Fig. 4. Generic Superstructure

\subsection{Mass Balance Equations}

The mass balance for the first four layers of activities illustrated by the value chain in this study is adopted from the work done by Wan et al [8]. The total number of palms harvested $F_{g}^{\text {out }}$ (palm/y) from plantation $g$ has to be less than available palms to ensure a sustainable harvesting process, as:

$$
F_{g}^{a v}>F_{g}^{\text {out }} \forall g
$$

Harvested sago palms from plantation $g$ are then converted into bio-resource $m$ before its sent to sago mill $f$. Currently, the only bio-resource $m$ sent to sago mills are sago logs. Therefore, given the conversion of palms to sago $\operatorname{logs} X_{g, \log }$, the total amount of sago logs sent to sago mill $f, F_{g, \log }^{\text {in }}(\log / \mathrm{y})$ can be determined via:

$$
F_{g, \log , f}^{\text {in }}=F_{g, f}^{\text {out }} X_{g, \log } \forall g
$$

The total sago logs transported to sago mill $f$ is the determined via:

$$
F_{f}^{i n}=\sum_{g=1}^{G} F_{g, \log , f}^{i n} \forall f
$$

It is noted that sago logs can be transported via roads or river. However, only road transportation is considered in this study, similar to the study done by Wan et al.[8]. Given a lorry capacity $\mathrm{C}_{\text {weightlim }}^{\text {lorry }}\left(\mathrm{t} /\right.$ trip) and weight per $\log \mathrm{W}_{\log }(\mathrm{t} / \log )$, the number of trips needed to transport the sago $\operatorname{logs}$ from plantation $g$ to sago mill $f n_{g, f}^{\text {trip }}$ (trip) is determined via 


$$
n_{g, f}^{\text {trip }} \geq \frac{F_{g, \log , f}^{\text {in }} W_{\log }}{C_{\text {weight lim }}^{\text {lorry }}} \quad \forall g \forall f
$$

In sago mill $f$, the sago logs are converted into sago starch, producing sago wastes as byproducts, labelled as product $p$ in this study. To calculate the amount of starch produced from sago mill $f \operatorname{Starch}^{f}(\mathrm{t} / \mathrm{y})$, Equation (5) is formulated.

$$
\text { Starch }^{f}=\sum_{g=1}^{G} F_{g, \log , f}^{i n} X_{g, \log , \text { starch }} \forall f
$$

Given that each sago mill $f$ has a production capacity $F_{\text {Starch }}^{a v}(\mathrm{t} / \mathrm{y})$ which cannot be exceeded, hence, the equation below is included in the model

$$
\operatorname{Starch}^{f}<F_{\text {Starch }}^{a v} \forall f
$$

To satisfy sago demand, StarchDemand (t/y) which is set at 32,000 t/y in this study, the Equation (7) is added into the model.

$$
\text { StarchDemand }=\sum_{f=1}^{F} \text { starch }^{f}
$$

The amount of product $p$ produced from sago mill $f$ from SSEP $F_{f, p}^{o u t}$ is calculated via:

$$
F_{f, p}^{\text {out }}=\operatorname{Starch}^{f} X_{\text {starch, },} \forall f \forall p
$$

Hence, the amount of product $p$ produced $F_{p}^{i n}$ (t/y) from all sago mills is calculated as:

$$
F_{p}^{\text {in }}=\sum_{f=1}^{F} F_{f, p}^{\text {out }} \forall p
$$

Product $p$ is then sent to technology $1 c$ to be converted into intermediate $d$. The amount of product $p$ sent to technology $1 c F_{c}^{i n}(\mathrm{t} / \mathrm{y})$ is as

$$
F_{c}^{i n}=\sum_{p=1}^{P} F_{p, c}^{i n} \forall c
$$

In technology 1 , the amount of intermediate $d$ produced from product $p$ is dependent on the conversion $\mathrm{X}_{\mathrm{p}, \mathrm{b}}^{c}$, as:

$$
F_{c, d}^{\text {out }}=F_{c}^{\text {in }} \mathrm{X}_{\mathrm{p}, \mathrm{d}}^{c} \forall c \forall d
$$

Given the conversion $\mathrm{X}_{\mathrm{p}, \mathrm{b}}^{c}$, the amount of intermediate $d$ produced $F_{d}^{i n}(\mathrm{t} / \mathrm{y})$ can be calculated via:

$$
F_{d}^{i n}=\sum_{c=1}^{C} F_{c, d}^{o u t} \forall d
$$

Next, intermediate $d$ is the distributed to technology $2 e$ via: 


$$
F_{d}^{o u t}=\sum_{e=1}^{E} F_{d, e}^{o u t} \forall d
$$

Between these 2 layers of activities, conversion of Intermediate $d$ into suitable unit for Technology $2 e \mathrm{X}_{\mathrm{d}, \mathrm{e}}^{\text {unit }}$ might be needed (e.g., conversion of syngas to power unit GJ in for CHP in technology $2 e$ ). Therefore, the flow into technology $2 e$ is calculated via:

$$
F_{d, e}^{\text {in }}=F_{d, e}^{\text {out }} \mathrm{X}_{\mathrm{d}, \mathrm{e}}^{\text {unit }} \quad \forall d \forall e
$$

Hence, the amount received in technology 2 e $F_{e}^{\text {in }}$ (unit/y)can be calculated via:

$$
F_{e}^{i n}=\sum_{d=1}^{D} F_{d, e}^{i n} \forall e
$$

Similar to technology $1 c$, the amount produced from technology $2 e$ is dependent on the conversion $\mathrm{X}_{\mathrm{d}, \mathrm{z}}^{e}$

$$
F_{e, z}^{\text {out }}=F_{e, z}^{\text {out }} \mathrm{X}_{\mathrm{d}, \mathrm{z}}^{e} \quad \forall e \forall z
$$

Given the conversion $\mathrm{X}_{\mathrm{d}, \mathrm{z}}^{e}$, the amount of end product $z$ produced $F_{z}^{\text {in }}$ (unit/y) can be calculated via:

$$
F_{z}^{i n}=\sum_{e=1}^{E} F_{e, z}^{o u t} \forall d
$$

\subsection{Economic Performance Evaluation Equations}

The economics performance of each activities is evaluated to determine the economic performance of the proposed value chain as a whole. In this study, the economic performance is defined as the difference between revenue obtained from production of end product $z$ and the cost associated with the production of end product $z$. Similar to mass balance formulation at section 2.4, the economic performance of the first four layers of activities in the value chain is formulated with reference to the approach taken by Wan et al in [8]. At plantation $g$, the cost considered is the harvesting cost, as well as the transportation of bio resource $m$ (sago $\operatorname{logs}$ ) to sago mill $f$. the total cost of harvesting Tot $\cos t_{g}^{\text {Harvest }}(\mathrm{USD} / \mathrm{y})$, as well as total cost of transportation Tot $\cos t^{\text {Transportation }}(\mathrm{USD} / \mathrm{y})$ is calculated via:

$$
\begin{gathered}
\text { Tot } \cos t_{g}^{\text {Harvest }}=\sum_{g=1}^{G} U \cos t_{g}^{\text {Harvest }} F_{g}^{\text {out }} \\
\text { Tot } \cos t^{\text {Transportation }}=\sum_{f=1}^{F} \sum_{g=1}^{G} U \cos t^{k m} d_{g, f}^{\text {trip }} n_{g, f}^{\text {trip }}
\end{gathered}
$$

where $U \cos t_{g}^{\text {Harvest }}$ is the cost of harvesting at plantation $g, U \cos t^{k m}(\mathrm{USD} / \mathrm{palm})$ is cost of transportation per $\mathrm{km} \mathrm{USD} / \mathrm{km})$ and $d_{g, f}^{\text {trip }}(\mathrm{km})$ is the distance between plantation $g$ and sago mill $f$. Hence the total cost incurred by all plantations Tot $\cos t^{\text {Plantation }}$ (USD/y) is as: 


$$
\text { Tot } \cos t^{\text {Plantation }}=\text { Tot } \cos t_{g}^{\text {Harvest }}+\text { Tot } \cos t_{g}^{\text {Transportation }}
$$

In sago mill $f$, the cost considered is the cost of process Tot $\cos t_{f}^{\text {Process }}$ (e.g., electricity, water consumption) as well as raw material cost $T o t \cos t_{f}^{\text {Material }}$ for the production of sago starch. In this study, sago wastes are assumed to be produced from SSEP without cost. The cost of transportation to refinery site for conversion via technology $1 c$ is also not considered in this study. Therefore, the total cost of the sago mill is calculated by summing the cost of process and raw materials as showed in Equations (21) - (23):

$$
\begin{aligned}
& \text { Tot } \cos t_{f}^{\text {Material }}=\sum_{f=1}^{F} U \cos t_{f}^{\text {Material }} \text { Starch } \\
& \text { Tot } \cos t_{f}^{\text {Process }}=\sum_{f=1}^{F} U \cos t_{f}^{\text {Process }} \text { Starch } \\
& \text { Tot } \cos t^{\text {mill }}=\text { Tot } \cos t^{\text {material }}+\text { Tot } \cos t^{\text {process }}
\end{aligned}
$$

where $U \cos t_{f}^{\text {Material }}(\mathrm{USD} / \mathrm{t})$ and $U \cos t_{f}^{\text {Process }}(\mathrm{USD} / \mathrm{t})$ is the process and raw material unit cost to produce one tonne of sago starch in sago mill $f$. The total cost of production Tot $\cos t^{\text {Prod }}(\mathrm{USD} / \mathrm{y})$ is the calculated via:

$$
\text { Tot } \cos t^{\text {Prod }}=\text { Tot } \cos t^{\text {plantation }}+\text { Tot } \cos t^{\text {mill }}
$$

Next, the cost of the product $p$ Tot $\cos t_{p}(\mathrm{USD} / \mathrm{y})$ is considered in this study via:

$$
\text { Tot } \cos t_{p}=\sum_{p=1}^{P} \mathrm{UCost}_{\mathrm{p}} F_{p}^{i n}
$$

where $\mathrm{UCost}_{\mathrm{p}}$ is unit cost of product $p$ (USD/t). In order to produce intermediate $d$ from Technology $1 c$, there will be cost associated, which is calculated via:

$$
\text { Tot } \cos t_{b}=\sum_{b=1}^{B} \mathrm{UCost}_{b} F_{b}^{\text {out }}
$$

where $\mathrm{UCost}_{b}(\mathrm{USD} / \mathrm{t})$ is the unit cost of converting product $p$ to intermediate $d$. Similarly, the cost to produce end product $z$ via Technology $2 e$ is calculated via:

$$
T o t \cos t_{e}=\sum_{e=1}^{E} \sum_{z=1}^{Z} \mathrm{UCost}_{e} F_{e}^{i n}
$$

where $\mathrm{UCost}_{e}(\mathrm{USD} / \mathrm{t})$ is the unit cost of converting Intermediate $d$ into End Product $\mathrm{Z}$ via technology $2 e$. Lastly, the total cost of the value chain $\operatorname{Tot} \operatorname{Cos} t^{\text {Overall }}(\mathrm{USD} / \mathrm{y})$ is calculated via:

$$
\begin{aligned}
& \text { Tot } \operatorname{Cos} t^{\text {Overall }}=\text { Tot } \cos t_{\text {production }}+\text { Tot } \cos t_{b}+ \\
& \text { Tot } \cos t_{c}+\text { Tot } \cos t_{d}+\text { Tot } \cos t_{e}
\end{aligned}
$$


Next, the revenue from the proposed value chain $\operatorname{Tot} \operatorname{Re} v_{z}(\mathrm{USD} / \mathrm{y})$ can be calculated via:

$$
\text { Tot } \operatorname{Re} v_{z}=\sum_{z=1}^{Z} \operatorname{Price}_{z} F_{z}^{i n}
$$

where Price $z$ is the unit price for the End Product $z$ produced. Therefore, in order to evaluate the economic performance of the proposed value chain, the overall profit Tot Profit ${ }^{\text {Overall }}(\mathrm{USD} / \mathrm{y})$ is calculated via:

$$
\text { Tot } \operatorname{Pr} o f i t^{\text {Overall }}=\text { Tot } \operatorname{Re} v_{z}-\text { Tot } \operatorname{Cos} t^{\text {Overall }}
$$

\subsection{Carbon Footprint (CFP) Computation Equations}

The formulation of CFP is done with reference to CFP formulation done by Wan et al. [8]. The author considered the land use change (LUC) emission from the commercialisation of land for plantation. Given that the yearly emission per metre square from LUC $U C F P_{g}^{L U C}$ $\left(\mathrm{kg} / \mathrm{m}^{2} . \mathrm{y}\right)$ is 2.33 as reported by Fargione et al. [11]. The total land use change carbon footprint from plantation $g$ TotCFP ${ }^{L U C}\left(\mathrm{~kg} \mathrm{CO}^{2} / \mathrm{y}\right)$ can be calculated via:

$$
\begin{gathered}
\text { TotCFP } P_{\text {plantation }}^{L U C}=\sum_{g=1}^{G} A_{g} U C F P_{g}^{L U C} \\
\text { TotCFP } P_{\text {plantation }}^{\text {Fuel }}=\sum_{f=1}^{F} U C F P_{k m}^{f u e l} n_{g, f}^{\text {trip }} d_{g, f}^{\text {trip }} \\
\text { TotCFP plantation }=\text { TotCFP plantation }+ \text { TotCFP plantation }
\end{gathered}
$$

Next, the total amount of power and fuel consumed in sago mill $f$ is determined in order to calculate the CFP emission from sago mill $f$. The CFP from power consumption and fuel consumption is calculated via:

$$
\text { TotCFP } P_{\text {mill }}=\sum_{f=1}^{F} U C F P_{K W h}^{\text {Power }} E_{f, \text { starch }} \text { Starch }^{f}
$$

Thus the total CFP emission from production process can be calculated via:

$$
\text { TotCFP } P^{\text {Production }}=\text { TotCFP } P_{\text {mill }}^{\text {Power }}+\text { TotCFP } \text { plantation }_{\text {total }}
$$

Considering that product $p$ in this study represents the sago waste produced from SSEP, the CFP emission for production of product $p$ is assumed to be zero. However, the CFP emission from conversion of product $p$ to intermediate $d$ via technology $c$ is considered in this study as:

$$
\operatorname{TotCFP}_{b}^{\text {Total }}=\sum_{b=1}^{B} U \operatorname{CFP}_{b} F_{b}^{\text {out }}
$$

Next, the CFP emission from conversion of intermediate $d$ to end product $z$ via technology $2 e$ is the sum of the base CFP emission from processing intermediate $d$ and also the specific power consumption of producing end product $z$ via technology $2 e$. 


$$
\begin{aligned}
& \operatorname{TotCFP}_{e}^{\text {Base }}=\sum_{e=1}^{E} \operatorname{UCFP}_{e}^{\text {base }} F_{e}^{\text {in }} \\
& \operatorname{TotCFP}_{e}^{\text {Specific }}=\sum_{z=1}^{Z} \sum_{e=1}^{E} U C F P_{e, z}^{\text {specific }} F_{e, z}^{\text {out }}
\end{aligned}
$$

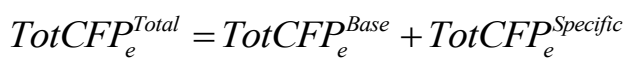

The total overall CFP $T o t C F P^{\text {Overall }}\left(\mathrm{kg} \mathrm{CO}^{2} / \mathrm{y}\right)$ is calculated via:

$$
\begin{aligned}
& \operatorname{Tot} C F P^{\text {Overall }}=\operatorname{Tot} C F P_{\text {plantation }}^{\text {total }}+\operatorname{Tot} C F P_{\text {mill }} \\
& +\operatorname{TotCFP}_{b}^{\text {Total }}+\operatorname{TotCFP}_{e}^{\text {Total }}
\end{aligned}
$$

\subsection{Fuzzy-Based Optimization Approach Equations}

Cost and Environmental objectives are often contradictory, a fuzzy-based optimisation approach is adopted in this study to select the optimum pathway for conversion of sago waste to value -added products. Using the 'min-max' aggregation concept in fuzzy optimisation, the optimum pathway can be obtained by maximising the least satisfied constraints. Fuzzy optimisation combines multiple objectives into a single variable, $\lambda$, having a range of 0 to 1 . In this study, the objectives are integrated into $\lambda$ as shown in the equations below:

$$
\begin{gathered}
\frac{C F P^{U L}-\operatorname{TotCFP}}{C F P^{U L}-C F P^{L L}} \geq \lambda \\
\frac{\text { Tot } \operatorname{Pr} o f i t-\operatorname{Pr} o f i t^{L L}}{\operatorname{Pr} o f i t^{U L}-\operatorname{Pr} o f i t^{L L}} \geq \lambda
\end{gathered}
$$

where TotCFP and Tot Profit, are the carbon footprint and profit generated by utilizing the optimum pathway for conversion of sago wastes. Meanwhile, $C F P^{L L}$ and $C F P^{U L}$ are the pre-determined lower and upper limit of the carbon footprint generated, same goes for $\operatorname{Pr} o f i t^{U L}$ and Profit ${ }^{L L}$ for profit generated. These upper and lower limit are determined by extracting data from evaluation results of the model at different objectives.

It is noted that each objective has a predetermined fuzzy range, represented by a linear function within the lower and upper limit, as shown in Fig 2.

Fig. 2 (a) illustrates the maximization case, where $\lambda$ approaches 1 when the objective, Tot Profit approaches the upper limit, Profit ${ }^{U L}$ of the fuzzy approach. On the contrary, Fig. 2 (b) demonstrates the minimization case, where $\lambda$ approaches 1 when the objective, TotCFP approaches the lower limit, $C F P^{U L}$. 


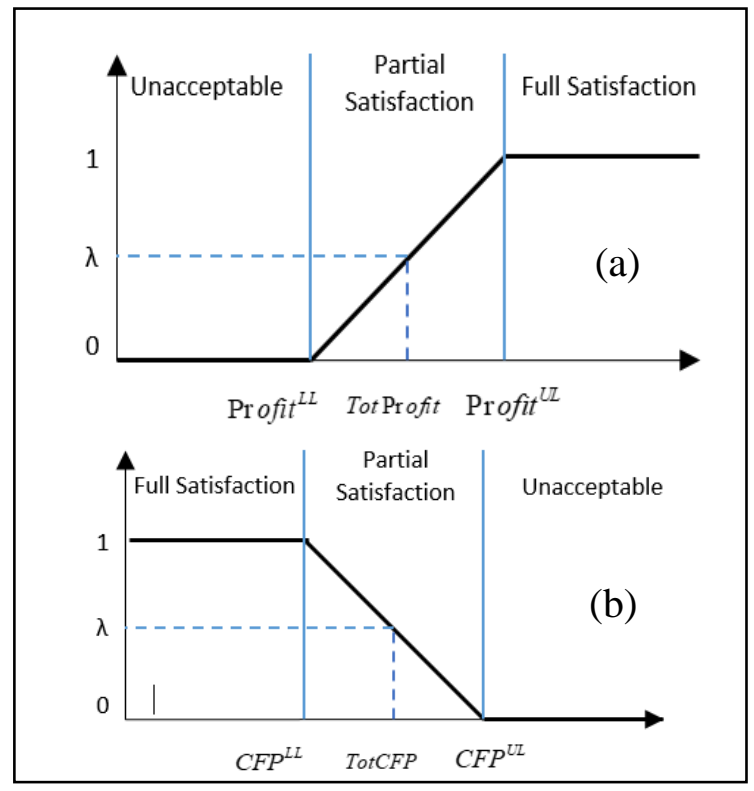

Fig. 2. The Concept of Fuzzy

In order to generate an optimum pathway for the conversion of sago waste while maximizing profit and minimizing carbon footprint, Eq. (40) and (41) are included in the optimization model, and solved simultaneously by maximising the degree of satisfaction, $\lambda$. This mixed integer linear programming (MILP) model is solved via Lingo v17.0 in a Lenovo Ideapad 700 with Intel Core i7-6700HQ (2.6 GHz) and 8GB ram running on 64-bit operating system.

\section{Case Study}

Fig 6 shows the case study superstructure that with all the possible pathways of activities from the proposed value chain in this study. In this case study, plantations from Mukah, Dalat, Saratok and Betong are considered, with sago logs as the only bio-resource produced from the considered sago plantations. The sago mills considered in this study are the ones located around the plantations.

The sago mills products considered in this study are the sago fibers, sago wastes, and sago wastewater, which are produced simultaneously in the sago mill during SSEP. In this study, eight different conversion technology are considered in technology 1 that produces primarily four different intermediates, which will be sent to technology 2 considered in this study. The end product considered in this study consists of high value product from agriculture biomass that has been intensively studied recently. Data from superstructure, such as amount of palms available annually, capacities of sago mill and distance between sago mill and plantation can be found is taken from data reported by Wan et al. [8]. For this study, the conversion rate of palm to sago $\log X_{\mathrm{g}, \log }$ are taken as $10 \operatorname{logs} / \mathrm{palm}$, the weight of $\log \mathrm{W}_{\log }$ is taken as $0.05 \mathrm{t} / \log$. Different plantation $\mathrm{g}$ produces palms with different starch content due to different soil conditions, which can also be found in [8]. To determine the economic and environmental performance of the value chain proposed in this study, unit costs and CFP emission of producing intermediate $d$ and end product $z$ via 
technology $1 c$ and technology $2 e$ are estimated from literature and summarized in Table 1 [12]-[18].

Table 1. Conversion, Cost and CFP data

\begin{tabular}{|c|c|c|c|c|c|}
\hline & Feed Type & $\begin{array}{l}\text { Product } \\
\text { Type }\end{array}$ & $\begin{array}{l}\text { Conversion } \\
\text { (product/feed) }\end{array}$ & $\begin{array}{l}\text { Cost } \\
\text { (USD/Tonne } \\
\text { Product) }\end{array}$ & $\begin{array}{l}\text { CFP } \\
(\mathrm{kg} \\
\mathrm{CO}_{2} / \text { tonne } \\
\text { Product })\end{array}$ \\
\hline \multirow{2}{*}{ Alkali Based } & Sago Fiber & Glucose & 0.4828 & \multirow{2}{*}{650} & \multirow{2}{*}{467.48} \\
\hline & Sago Bark & Glucose & 0.16401 & & \\
\hline \multirow{2}{*}{ Acid Based } & Sago Fiber & Glucose & 0.5440 & \multirow{2}{*}{420} & \multirow{2}{*}{503.44} \\
\hline & Sago Bark & Glucose & 0.1848 & & \\
\hline \multirow{2}{*}{$\begin{array}{l}\text { Steam } \\
\text { Explosion }\end{array}$} & Sago Fiber & Glucose & 0.6120 & \multirow{2}{*}{430} & \multirow{2}{*}{521.42} \\
\hline & Sago Bark & Glucose & 0.2079 & & \\
\hline \multirow{2}{*}{$\begin{array}{l}\text { Liquid Hot } \\
\text { Water }\end{array}$} & Sago Fiber & Glucose & 0.6120 & \multirow{2}{*}{790} & \multirow{2}{*}{467.48} \\
\hline & Sago Bark & Glucose & 0.2079 & & \\
\hline \multirow{2}{*}{$\begin{array}{l}\text { Irradiation } \\
\text { Method }\end{array}$} & Sago Fiber & Glucose & 0.2244 & \multirow{2}{*}{370.58} & \multirow{2}{*}{317.15} \\
\hline & Sago Bark & Glucose & 0.0762 & & \\
\hline \multirow{2}{*}{ Gasification } & Sago Fiber & Syngas & 0.2271 & \multirow{2}{*}{45,200} & \multirow{2}{*}{2,200} \\
\hline & Sago Bark & Syngas & 0.2220 & & \\
\hline \multirow{2}{*}{ Pyrolysis } & Sago Fiber & Bio-Oil & 0.3200 & \multirow{2}{*}{89,630} & \multirow{2}{*}{1,727} \\
\hline & Sago Bark & Bio-Oil & 0.3200 & & \\
\hline $\begin{array}{l}\text { Anaerobic } \\
\text { Digestion }\end{array}$ & $\begin{array}{l}\text { Sago } \\
\text { Waste } \\
\text { Water }\end{array}$ & Bio Gas & 1.7250 & 4,400 & 0 \\
\hline \multirow{3}{*}{ Fermentation } & Glucose & Butanol & 0.0857 & 1,370 & $12,652.53$ \\
\hline & Glucose & Ethanol & 0.2910 & 874.52 & $5,977.79$ \\
\hline & Glucose & Hydrogen & 0.0111 & 5400 & $13,055.82$ \\
\hline \multirow{2}{*}{ CHP } & GJ & Power(GJ) & 0.2222 & 1.55 & 0 \\
\hline & GJ & Heat(GJ) & 0.8000 & 16.95 & 0 \\
\hline
\end{tabular}




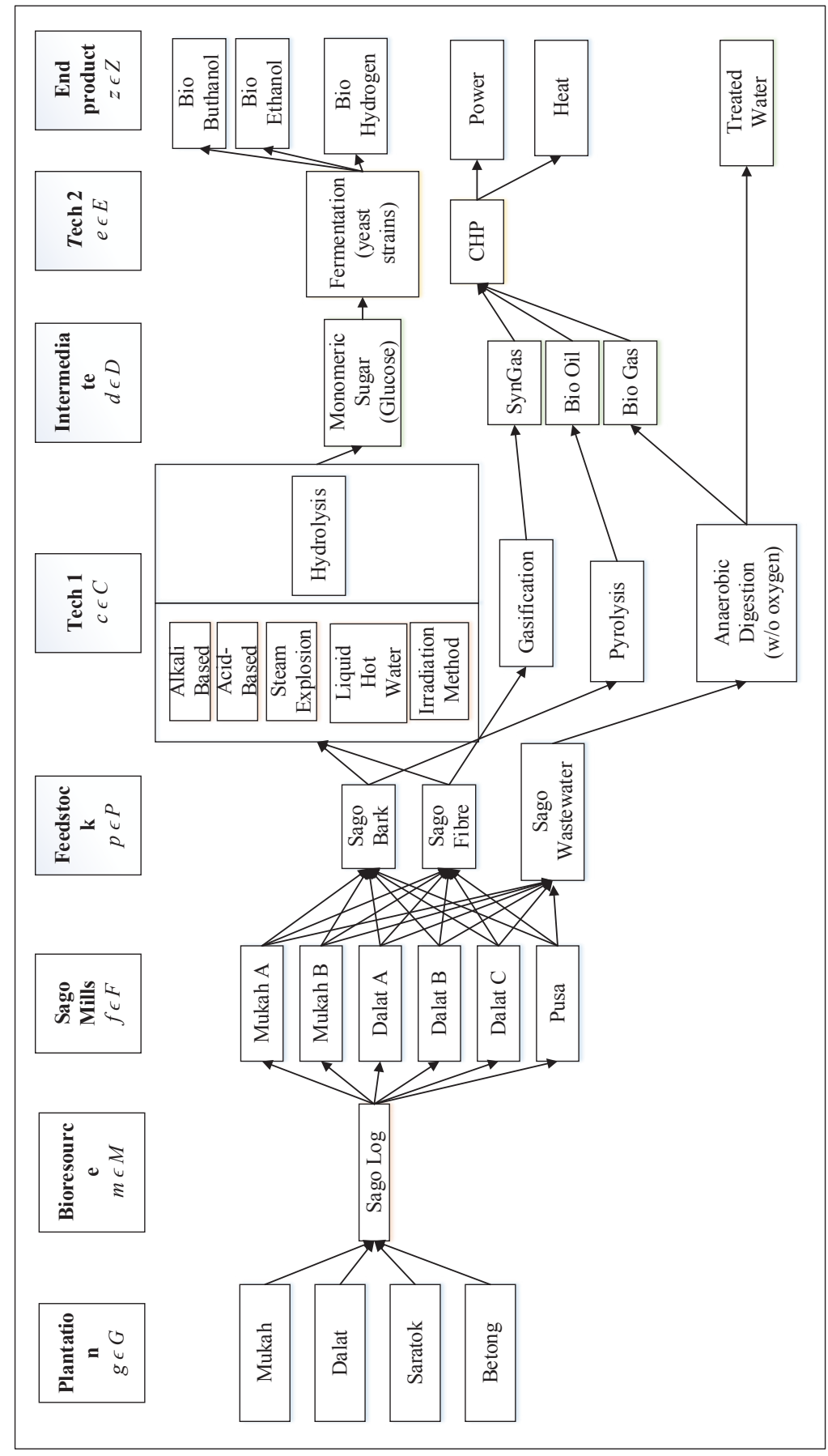

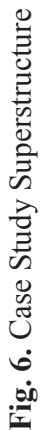




\subsection{Results and Discussion}

To solve the case study, the upper and lower fuzzy limit is pre-determined by solving the objectives individually (e.g., maximize profit, minimize CFP emission) without mutual interaction between objectives. The single objective optimization results are shown in Table 2. Based on the results on, the upper and lower fuzzy limits is coded into the model and solved via Lingo 16.0 in a Lenovo Ideapad 700 with Intel Core i7-6700HQ (2.6 GHz) and 8GB ram running on 64-bit operating system. The CPU time to obtain the maximum global optimal solution for degree of satisfaction $\lambda$ is approximately within $5 \mathrm{~s}$. In addition, Table 3-6 illustrate the flow rate between layers at different objectives.

Table 2. Total Profit and CFP in multiple objectives

\begin{tabular}{lll}
\hline Objective Functions & Total Profit (Million USD/y) & Total CFP (tonne CO2/y) \\
\hline Max Total Profit & 342.90 & $779,803.00$ \\
Min Total CFP & -4.30 & $768,777.90$ \\
\hline
\end{tabular}

Table 3. Mass Flowrates of logs from plantations to sago mills with objective function minimize TotCFP ${ }^{\text {Overall }}$, maximize Tot $\operatorname{Pr}$ ofit ${ }^{\text {Overall }}$ and maximize $\lambda$.

\begin{tabular}{|c|c|c|c|c|c|c|}
\hline \multicolumn{7}{|c|}{ Flow Rate from sago plantation to sago mill $(\log / \mathrm{y})$} \\
\hline & \multicolumn{6}{|c|}{ minimize TotCFP $^{\text {Overall }}$} \\
\hline & Mukah A & Mukah B & Dalat A & Dalat B & Dalat C & Pusa \\
\hline Mukah & 0 & 375,000 & 0 & 0 & 200 & 0 \\
\hline Dalat & 0 & 0 & 302,400 & 317,400 & 204,600 & 0 \\
\hline Saratok & 0 & 0 & 0 & 0 & 0 & 220,000 \\
\hline \multirow[t]{3}{*}{ Betong } & 0 & 0 & 0 & 0 & 0 & 0 \\
\hline & \multicolumn{6}{|c|}{ maximize Tot $\operatorname{Pr} o f i t^{\text {Overall }}$} \\
\hline & Mukah A & Mukah B & Dalat A & Dalat B & Dalat C & Pusa \\
\hline Mukah & 0 & 374,200 & 0 & 0 & 0 & 0 \\
\hline Dalat & 0 & 600 & 302,400 & 343,600 & 178,800 & 0 \\
\hline Saratok & 0 & 0 & 0 & 0 & 0 & 220,000 \\
\hline \multirow[t]{3}{*}{ Betong } & 0 & 0 & 0 & 0 & 0 & 0 \\
\hline & \multicolumn{6}{|c|}{$\operatorname{maximize} \lambda$} \\
\hline & Mukah A & Mukah B & Dalat A & Dalat B & Dalat C & Pusa \\
\hline Mukah & 0 & 0 & 0 & 0 & 0 & 0 \\
\hline Dalat & 200 & 343,600 & 302,400 & 343,600 & 343,600 & 0 \\
\hline Saratok & 0 & 0 & 0 & 0 & 0 & 0 \\
\hline Betong & 0 & 0 & 0 & 0 & 0 & 0 \\
\hline
\end{tabular}


Table 4. Mass Flow Rate of Sago Wastes from sago mills with objective function minimize TotCFP ${ }^{\text {Overall }}$, maximize Tot Pr ofit ${ }^{\text {Overall }}$ and maximize $\lambda$.

\begin{tabular}{|c|c|c|c|c|c|c|c|c|c|}
\hline \multicolumn{10}{|c|}{ Production of Sago wastes from Sago mills. } \\
\hline \multirow[t]{2}{*}{$\begin{array}{l}\text { Objective } \\
\mathrm{s}\end{array}$} & \multicolumn{3}{|c|}{$\begin{array}{l}\text { minimize } \\
\text { TotCFP }\end{array}$} & \multicolumn{3}{|c|}{$\begin{array}{l}\text { maximize } \\
\text { Tot } \operatorname{Pr} \text { ofit }{ }^{\text {Overall }}\end{array}$} & \multicolumn{3}{|c|}{$\operatorname{maximize} \lambda$} \\
\hline & SF & SB & SW & SF & SB & SW & SF & SB & SW \\
\hline Mukah A & 0 & 0 & 0 & 0 & 0 & 0 & 4.8 & 19.2 & 96 \\
\hline Mukah B & $\begin{array}{l}8,25 \\
0\end{array}$ & $\begin{array}{l}33,00 \\
0\end{array}$ & $\begin{array}{l}165,00 \\
0\end{array}$ & $\begin{array}{l}8,24 \\
6\end{array}$ & $\begin{array}{l}32,98 \\
7\end{array}$ & $\begin{array}{l}164,93 \\
6\end{array}$ & $\begin{array}{l}9,24 \\
6\end{array}$ & $\begin{array}{l}32,98 \\
5\end{array}$ & $\begin{array}{l}164,92 \\
8\end{array}$ \\
\hline Dalat A & $\begin{array}{l}7,25 \\
7\end{array}$ & $\begin{array}{l}29,03 \\
0\end{array}$ & $\begin{array}{l}145,15 \\
2\end{array}$ & $\begin{array}{l}7,25 \\
7\end{array}$ & $\begin{array}{l}29,03 \\
0\end{array}$ & $\begin{array}{l}145,15 \\
2\end{array}$ & $\begin{array}{l}7,25 \\
7\end{array}$ & 29030 & $\begin{array}{l}145,15 \\
2\end{array}$ \\
\hline Dalat B & $\begin{array}{l}7,61 \\
7\end{array}$ & $\begin{array}{l}30,47 \\
0\end{array}$ & $\begin{array}{l}152,35 \\
2\end{array}$ & $\begin{array}{l}8,24 \\
6\end{array}$ & $\begin{array}{l}32,98 \\
5\end{array}$ & $\begin{array}{l}164,92 \\
8\end{array}$ & $\begin{array}{l}8,24 \\
6\end{array}$ & 3,295 & $\begin{array}{l}164,92 \\
8\end{array}$ \\
\hline Dalat C & $\begin{array}{l}4,91 \\
4\end{array}$ & $\begin{array}{l}19,65 \\
9\end{array}$ & 98,296 & $\begin{array}{l}4,29 \\
1\end{array}$ & $\begin{array}{l}17,16 \\
4\end{array}$ & 85,824 & $\begin{array}{l}8,24 \\
6\end{array}$ & 3,295 & $\begin{array}{l}164,92 \\
8\end{array}$ \\
\hline Pusa & $\begin{array}{l}3,96 \\
0\end{array}$ & 15840 & 79,200 & $\begin{array}{l}3,96 \\
0\end{array}$ & 1,584 & 79,200 & 0 & 0 & 0 \\
\hline
\end{tabular}

Table 5. Mass Flow Rate of intermediate $d$ into technology 1 with objective function minimize TotCFP $P^{\text {Overall }}$, maximize Tot Profit ${ }^{\text {Overall }}$ and maximize $\lambda$.

\begin{tabular}{|c|c|c|c|c|c|c|c|c|c|}
\hline & \multicolumn{3}{|c|}{$\begin{array}{l}\text { minimize } \\
\text { TotCFP }\end{array}$} & \multicolumn{3}{|c|}{$\begin{array}{l}\text { maximize } \\
\text { Tot } \operatorname{Pr} \text { ofit }{ }^{\text {Overall }}\end{array}$} & \multicolumn{3}{|c|}{$\begin{array}{l}\text { maximize } \\
\lambda\end{array}$} \\
\hline & $\mathrm{SF}$ & SB & SW & SF & SB & SW & SF & SB & SW \\
\hline $\begin{array}{l}\text { Irradiation } \\
\text { Method }\end{array}$ & 0 & $\begin{array}{l}128,0 \\
00\end{array}$ & 0 & 0 & 0 & 0 & 0 & $\begin{array}{l}128,0 \\
06\end{array}$ & 0 \\
\hline Gasification & 0 & 0 & 0 & 0 & 0 & 0 & $\begin{array}{l}3,06 \\
8\end{array}$ & 0 & 0 \\
\hline Pyrolysis & $\begin{array}{l}32,0 \\
00\end{array}$ & 0 & 0 & $\begin{array}{l}32,0 \\
02\end{array}$ & $\begin{array}{l}128,0 \\
08\end{array}$ & 0 & $\begin{array}{l}28,9 \\
33\end{array}$ & 0 & 0 \\
\hline $\begin{array}{l}\text { Anerobic } \\
\text { Digestion }\end{array}$ & 0 & 0 & $\begin{array}{l}640,0 \\
00\end{array}$ & 0 & 0 & $\begin{array}{l}640,0 \\
40\end{array}$ & 0 & 0 & $\begin{array}{l}640,0 \\
32\end{array}$ \\
\hline
\end{tabular}

Table 6. Amount of Intermediate $d$ and End Product $z$ produced

\begin{tabular}{l|lll}
\hline & $\begin{array}{l}\text { minimize } \\
\text { TotCFP }\end{array}$ & maximize & maximize \\
& Tot Profit & \\
\hline Butanol & 0 & 0 & 0 \\
Ethanol & 2,839 & 0 & $2,839$. \\
Hydrogen & 0 & 0 & 0 \\
Power & $8,480,067$ & $8,716,897$ & $8,523,204$ \\
Heat & 0 & 0 & 0 \\
\hline
\end{tabular}

An optimum sustainable sago value chain with degree of satisfaction, $\lambda$ of 0.8596 , a total profit of 294.2 million USD/y and CFP emission of 770.32 ton $\mathrm{CO}_{2} / \mathrm{y}$ is obtained as shown in Table . Furthermore, Table also shows the flow rate between activities in the optimum sago value chain at optimised solution. 
Based on the optimised result, only palms from Dalat is harvested, which is first processed into sago logs before sending into sago mill Dalat A, Dalat B, Dalat C and Pusa SSEP process. The SSEP process then produces sago waste SF, SB and SW. SF is then sent into gasification and pyrolysis to produce syngas and bio-oil respectively, while SB is sent for microwave irradiation pre-treatment, followed by hydrolysis to produce monomeric sugars such as glucose. SW is sent to for anaerobic digestion to produce biogas. The intermediates are then sent for further processing. Glucose undergoes fermentation to produce ethanol, while syngas, bio-oil and bio gas are sent to CHP to generate power. The amount of final products produced in this optimised sago value chain is $2,839.611 \mathrm{t} / \mathrm{y}$ of ethanol and 8,523,204 GJ/y of power.

Table 7. Mass Flow Rate of Optimized Sago Value chain

\begin{tabular}{l|ll|l}
\hline Pathways & Amount & Pathways & Amount \\
\hline Dalat - Sago Log & 133,340 & SF- Gasification & 3,068 \\
Sago Log - Dalat A & 343,600 & SF - Pyrolysis & 28,933 \\
Sago Log - Dalat B & 302,400 & SB- Irradiation Method & 128,005 \\
Sago Log - Dalat C & 343,600 & SW- Anaerobic Digestion & 640,032 \\
Sago Log - Pusa & 343,600 & Irradiation Method - Glucose & 9,758 \\
Dalat A - SF & 8,246 & Gasification - Syngas & 696 \\
\hline
\end{tabular}

Table 8. Mass Flow Rate of Optimized Sago Value chain (Continued)

\begin{tabular}{l|ll|l}
\hline Pathways & Amount & Pathways & Amount \\
\hline Dalat A - SB & 32,985 & Pyrolysis - Bio Oil & 9,258 \\
Dalat A - SW & 164,928 & Anaerobic Digestion - Bio Gas & $1,104,055$ \\
Dalat B - SF & 7,257 & Glucose - Fermentation & 9,758 \\
Dalat B - SB & 29,030 & Syngas - CHP & 696 \\
Dalat B - SW & 145,152 & Bio Oil - CHP & 9,258 \\
Dalat C - SF & 8,246 & Bio Gas - CHP & $1,104,055$ \\
Dalat C - SB & 32,985 & Fermentation - Bio Ethanol & 2,839 \\
Dalat C - SW & 164,928 & CHP - Power & $8,523,204$ \\
Pusa - SF & 8,246 & & \\
Pusa - SB & 32,985 & Total CFP & $770,324,800$ \\
Pusa - SW & 164,928 & Total Profit & $294,206,200$ \\
\hline
\end{tabular}




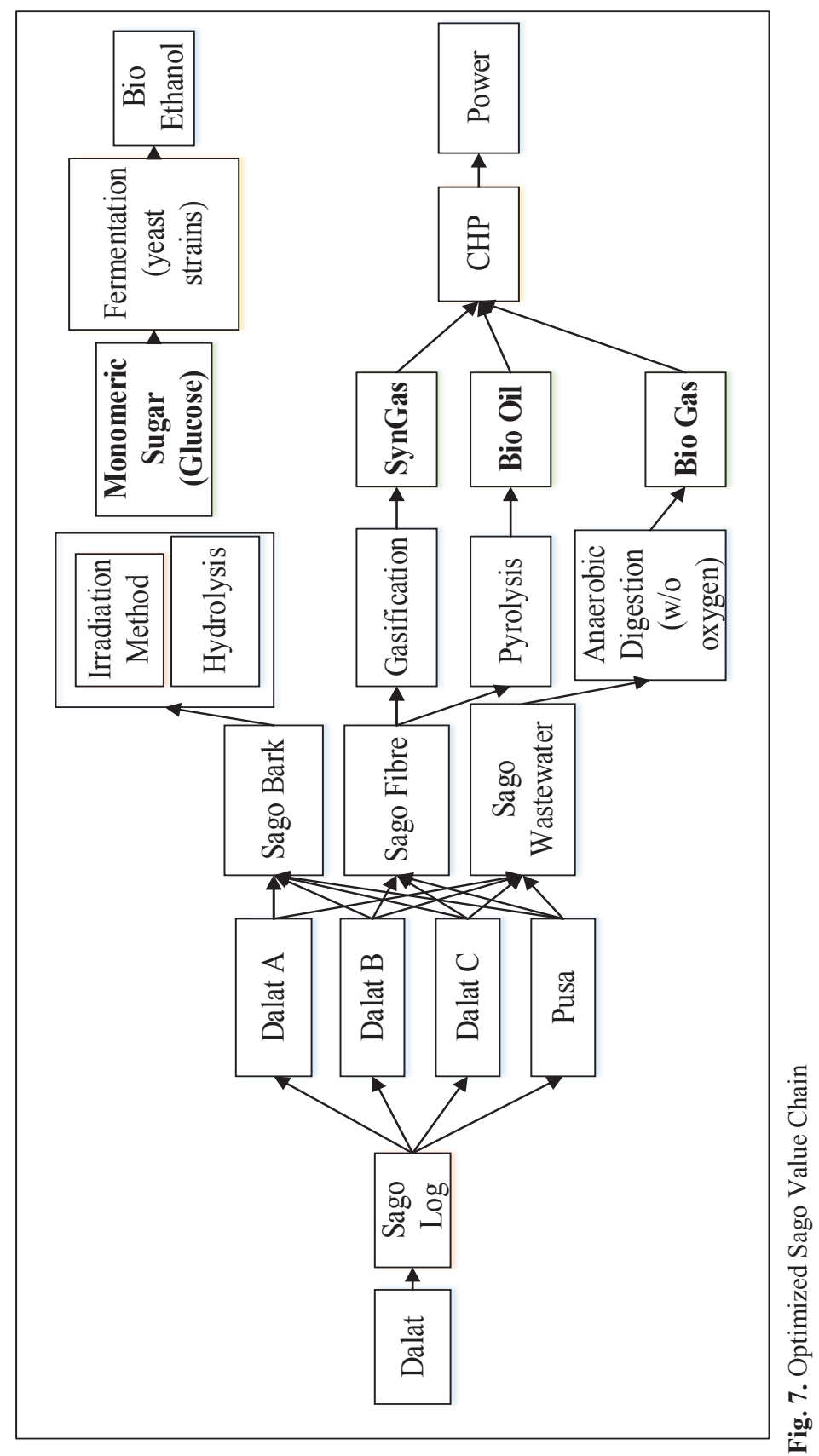




\section{Conclusions}

A fuzzy-based optimisation model approach that considers economic and environmental performance of the proposed sago value chain simultaneously is developed in this study. This model can be used as an analysis tool that aids decision making in selecting the most optimal pathway for conversion of sago waste to value added product while considering the environmental and economic impacts.

This model developed in this study is requires intensive data and is customized for sago industry in this study; however, with some modification, it can be applied in different agriculture industry to evaluate conversion pathways of agriculture biomass into valueadded products. Note that data such as yield, cost and CFP of crops might not be readily available and is subjected to the magnitude of attention and research on that specific agriculture industry. Sensitivity to uncertainties or changes in data is not considered in this study via robust optimization, which can be considered in the future.

The limitation of this study is that it only considers the sago wastes produced from the SSEP process in the sago mill, which can also be considered in future researches.

\section{References}

1. M. Flach, Sago palm, Diversity, 76, (1997).

2. FAO, Expert consultation on the establishment of a sago network for Asia and the Pacific, 1-83, (2013).

3. A. A. Karim, A. P. L. Tie, D. M. A. Manan, and I. S. M. Zaidul, Starch from the sago (Metroxylon sagu) palm tree - Properties, prospects, and challenges as a new industrial source for food and other uses, Comprehensive Reviews in Food Science and Food Safety, 7. 215-228, (2008).

4. D. S. Awg-Adeni, S. Abd-Aziz, K. Bujang, and M. A. Hassan, Bioconversion of sago residue into value added products, African J. Biotechnol., 9, 2016-2021, (2010).

5. D. S. Awg-Adeni, K. B. Bujang, S. Abd-Aziz, and M. A. Hassan, Recovery of Glucose from Residual Starch of Sago Hampas for Bioethanol Production, 2013, (2013).

6. M. Machines, Chapter 1, 1-11, (1995).

7. Y. K. Wan, J. Sadhukhan, and D. K. S. Ng, Techno-economic evaluations for feasibility of sago-based biorefinery, Part 2: Integrated bioethanol production and energy systems, Chem. Eng. Res. Des., 107, 102-116, (2016).

8. Y. K. Wan, R. T. L. Ng, D. K. S. Ng, K. B. Aviso, and R. R. Tan, Fuzzy multifootprint optimisation (FMFO) for synthesis of a sustainable value chain: Malaysian sago industry, J. Clean. Prod., 128, 62-76, (2016).

9. T. Koc and E. Bozdag, Measuring the degree of novelty of innovation based on Porter's value chain approach, Eur. J. Oper. Res., 257, 559-567, (2017).

10. D. H. S. Tay, D. K. S. Ng, N. E. Sammons, and M. R. Eden, Fuzzy optimization approach for the synthesis of a sustainable integrated biorefinery, Ind. Eng. Chem. Res., 50, 1652-1665, (2011).

11. J. Fargione, J. Hill, D. Tilman, S. Polasky, and P. Hawthorne, Land clearing and the biofuel carbon debt., Science, 319, 1235-8, (2008).

12. N. Nahar, D. Ripplinger, and S. W. Pryor, Process yield and economic trade-offs for enzymatic hydrolysis of alkaline pretreated corn stover, Biomass and Bioenergy, 99, 97-105, (2017). 
13. T. Eggeman and R. T. Elander, Process and economic analysis of pretreatment technologies, Bioresour. Technol., 96, 2019-2025, (2005).

14. T. S. Kannan, A. S. Ahmed, and F. N. Ani, Energy Efficient Microwave Irradiation of Sago Bark Waste (SBW) for Bioethanol Production, Adv. Mater. Res., 701, 249-253, (2013).

15. T. Pielhop, J. Amgarten, P. R. von Rohr, and M. H. Studer, Steam explosion pretreatment of softwood: the effect of the explosive decompression on enzymatic digestibility, Biotechnol. Biofuels, 9, 152, (2016).

16. P. Noparat, P. Prasertsan, S. O-Thong, and X. Pan, Dilute Acid Pretreatment of Oil Palm Trunk Biomass at High Temperature for Enzymatic Hydrolysis, in Energy Procedia, (2015), 79, 924-929.

17. D. Kumar and G. S. Murthy, Impact of pretreatment and downstream processing technologies on economics and energy in cellulosic ethanol production, Biotechnol. Biofuels, 4, 27, (2011).

18. P. Elaiyaraju and N. Partha, Biogas Production from Sago (Tapioca) Wastewater Using Anaerobic Batch Reactor, Energy Environ., 23, 631-645, (2012).

19. M. Ben Rabha, M.F. Boujmil, M. Saadoun, B. Bessaïs, Eur. Phys. J. Appl. Phys. (to be published)

20. F. De Lillo, F. Cecconi, G. Lacorata, A. Vulpiani, EPL, 84 (2008)

21. L. T. De Luca, Propulsion physics (EDP Sciences, Les Ulis, 2009) 